\title{
ARICA/TACNA: LOS CIRCUITOS ECONÓMICOS DE UN COMPLEJO URBANO TRANSFRONTERIZO*
}

\author{
ARICA/TACNA: THE ECONOMIC CIRCUITS OF \\ A TRANSBORDER URBAN COMPLEX
}

\author{
Haroldo Dilla Alfonso ${ }^{* *}$ y Camila Álvarez Torres**
}

\begin{abstract}
El surgimiento de complejos urbanos transfronterizos en América Latina coloca en un primer plano el estudio de los circuitos económicos, formales e informales, que les amalgaman. Arica/Tacna muestran una variedad de circuitos económicos, generalmente marcados por la informalidad, y que en lo fundamental se resuelven localmente. Ello plantea un reto heurístico en cuanto a la manera cómo estos circuitos generan transferencias de valores de una parte a la otra, dando lugar a un proceso de intercambio desigual favorable a la ciudad chilena. El artículo centra su atención en el análisis sociológico de tres circuitos: la compra de fuerza de trabajo peruana por el capital chileno, el llamado comercio hormiga y el consumo chileno en Tacna.
\end{abstract}

Palabras claves: Tacna, Arica, fronteras, complejos urbanos transfronterizos, intercambio desigual.

The emergence of trans-border urban complexes in Latin America places the study of their economic circuits in the foreground. The binomial Arica / Tacna shows a variety of economic circuits, generally marked by informality, that in the main are resolved locally. This poses a heuristic challenge in terms of how these circuits generate transfers of values from one part to the other, giving rise to a process of unequal exchange favorable to the Chilean city. The article focuses on the sociological analysis of three circuits: the purchase of Peruvian labor force by Chilean capital, the so-called ant trade and Chilean consumption in Tacna.

Key words: Arica, Tacna, borders, unequal exchange, trans-border urban complexes.

\section{Introducción}

Las fronteras contemporáneas son, crecientemente, espacios de interacción contradictoria de identidades, flujos económicos y poderes políticos. Son vectores de regiones dinámicas y de aglomeraciones urbanas cuyos funcionamientos sistémicos desbordan y violentan límites y jurisdicciones nacionales. Ello, dicho en pocas palabras, implica una subversión del sentido westfaliano de las fronteras como empalizadas. Las fronteras devienen mecanismos de subordinación de los otros, y de sus optimizaciones como factores de producción, consumo o manipulación simbólica. Se trata, como han sugerido Mezzadra y Neilson (2013), de "...la multiplicación de conexiones y desconexiones territoriales, económicas, sociales y culturales" que define la "...capacidad de jerarquización y estratificación de los bordes" (P. 7). Recordando a Foucault (2003), hablamos de un proceso de disciplinarización/normalización, una modalidad de control de los individuos y de los procesos en el tiempo y en el espacio. En contacto con ellas, las prácticas sociales consuetudinarias devienen anómicas, las mercancías se trocan en contrabandos, los trabajadores se convierten en aliens y la cultura del otro se representa como folclor.

Estas interacciones transfronterizas han provocado interesantes reflexiones en las ciencias sociales latinoamericanas. En lo que nos concierne -los sistemas territoriales transfronterizos- pudiéramos invocar trabajos como los de Valero (2002) sobre Táchira/Santander; Montenegro y Giménez (2006) sobre la frontera de Argentina, Brasil y Paraguay; de Oddone y Galantini (2015) sobre Monte Caseros/Bella Unión/Barra do Quarai; de Dilla (2016) sobre la frontera dominico/haitiana; Domínguez (2010) y Nogueira (2008) acerca de dos experiencias de "fronteras íntimas": Chuí/Chuy y Tabatinga/Puerto Leticia, respectivamente; Benedetti sobre las aglomeraciones urbanas en el cono sur; y Ruiz y Martínez (2015) sobre la frontera México/ Guatemala, entre otros.

Ubicadas en el borde que contacta a Chile y Perú, Tacna, con una población cercana a los 300 mil habitantes y Arica con unos 200 mil, constituyen

\footnotetext{
* $\quad$ Resultado Proyecto FONDECYT 1150812.

** Universidad Arturo Prat, Instituto de Estudios Internacionales. Correos electrónicos: hdillaalfonso@ gmail.com; cami.alvarez.to@gmail.com
} 
un complejo urbano transfronterizo (CUT) definido en Dilla (2015) como dos o más ciudades interrelacionadas por un límite fronterizo, que comparten un entorno ambiental, forman una economía regional interdependiente y asimétrica, sostienen relaciones formales e informales más allá de la economía, y sus habitantes comparten una percepción de mutua necesidad. Como tal, comparte cualidades con otros casos latinoamericanos, pero al mismo tiempo presenta especificidades, y en particular una de ellas condiciona su comportamiento: es lo que Jessop (2001) hubiera llamado una región autocontenida o larvada.

\section{La región autocontenida}

La geopolítica dictaminó, hace menos de un siglo, la separación jurisdiccional de Tacna y Arica. Dos ciudades que -sigo a González (2008, p. 13)eran "...dos pisos ecológicos complementarios y articulados económica, social y culturalmente". Y por ello los intercambios continuaron fluyendo en una u otra dirección. Pero han sido intercambios que involucran a las ciudades y sus entornos inmediatos. Tres cuartas partes de los chilenos que abarrotan las avenidas comerciales de Tacna son ariqueños, y el excelente puerto de Arica es intensamente usado -desde Perú- solo por los empresarios de Tacna. Como si la región, y el CUT que la vertebra, estuvieran limitados al íntimo contacto local.

Por razones de espacio es imposible seguir desarrollando esta idea ${ }^{1}$. Valga anotar que la noción de región transfronteriza autocontenida no hace alusión a grados de actividad -esta frontera es muy activa-, sino a la manera cómo este dinamismo se realiza. La concatenación de factores geopolíticos, históricos, geográficos y culturales determina que esta región no sea, como son otros CUT, un gozne de corredores extensos que penetran los espacios nacionales, involucran otras ciudades y van produciendo cadenas de valores que se relacionan con la economía global. Obviamente hay relaciones con otras ciudades (Iquique es un ejemplo) y también hay entradas y salidas respecto de la economía global, de lo que, como veremos, dan cuenta dispositivos como el puerto de Arica y las zonas francas establecidas en la zona. Pero son vínculos poco relevantes para las economías nacionales, y aún menos para los espacios económicos globalizados del Pacífico Sur. Los numerosos flujos económicos entre Tacna y Arica se realizan localmente y, en consecuencia, el ámbito económico transfronterizo se resuelve, en lo fundamental, en sí mismo.

Otro punto a tomar en cuenta es que el peso que en este ámbito tienen los procesos económicos formales es secundario. En comparación con otros pasos fronterizos chilenos, el tráfico mayorista formal de bienes que cruza el paso fronterizo Chacalluta/Santa Rosa es discreto. Es solo el 10\% de lo que transita por Los Libertadores en el borde con Argentina, y 15\% del tráfico que tiene lugar en Chungará, en la frontera con Bolivia. Según Aduanas de Chile (2016), en ese año entraron al territorio chileno por este puesto 263 mil toneladas de mercancías y salieron hacia Perú algo más de 200 mil. En total se trataría de menos de medio millón de toneladas, el 75\% de estas (y este es el dato más interesante) eran mercancías en tránsito. Es decir, un tipo de mercancía que pasa por territorio nacional rumbo a otros destinos, y para ello ese territorio constituye un no lugar. Por tanto, no es exagerado afirmar que la economía formal que anima la región transfronteriza no conduce a la formación de cadenas de valores o aglomeraciones económicas siquiera en este plano local, al mismo tiempo que debido a la pobre habilitación de servicios -por ejemplo, financieros- son flujos que regularmente bordean los espacios opacos de la informalidad. La reciente aparición de algunas producciones cooperadas en torno a la aceituna es un dato innovador, pero cuya modesta dimensión no reta esta conclusión.

La informalidad y la cotidianeidad son los signos distintivos del ámbito económico transfronterizo. En ello esta frontera no se distingue de otras en América Latina. Su distinción reside en el hecho de que las transacciones económicas están ligadas al tránsito de personas -pequeños traficantes, cargadores, comisionistas, consumidores, vendedores de fuerza de trabajo-, lo que eleva este puesto fronterizo al nivel del más transitado de Chile y uno de los más intensos de América Latina. En el 2016 -último del que poseemos estadísticas-ocurrieron 6,3 millones de cruces, más del $90 \%$ de ellos por chilenos y peruanos, casi a partes iguales ${ }^{2}$.

En este artículo analizaré el ámbito económico a partir de tres circuitos: la movilidad de fuerza de trabajo en función de la economía ariqueña, las prácticas sociales de comercio minorista denominadas comercio/hormiga, y los flujos de consumidores chilenos hacia Tacna, la actividad más fotogénica de la relación. Como anotaba antes, estos circuitos están signados por la informalidad y canalizados por 
prácticas consuetudinarias que actúan como "prácticas organizadoras", al decir de Certeau (2008), para esto existen relevantes estudios antecedentes como es el caso de Contreras, Tapia y Liberona (2017).

Ello planteó a nuestra investigación algunos problemas teóricos. El primero de ellos se refiere a la configuración de una economía política desde la regionalización económica transfronteriza. Evidentemente esta economía política no puede ser aprehendida desde lo que Harvey (2007) denominaba una coherencia estructurada de la producción, los intercambios y el consumo que para él definía la lógica de cualquier economía regional. La economía política transfronteriza se muestra como un tablero de Adelson, en que luces y sombras de superponen creando ilusiones que desorientan al observador. Pero en particular, esta muestra un marcado abigarramiento debido a su realización en una región autocontenida en el sentido antes explicado. En consecuencia, la región transfronteriza Arica/Tacna aparece siempre como un territorio en formación, que no logra madurar como un "modelo geoeconómico" basado en beneficios diferenciales regulares (Sohn (2014) p. 598). La imperfección del sistema regional no es anómala, sino la propia razón de su funcionamiento. Su aprehensión teórica requiere el concurso de los antropólogos.

Finalmente, y este es otro problema que asume el artículo, el (en lo fundamental) enclaustramiento localista no omite que, como en otras fronteras, se trate de una relación asimétrica que induce una transferencia neta de plusvalor de una parte a la otra, tal como lo que Emmanuel (1972) definió a escala global como un intercambio desigual, y que Kearney (2008) retomó en su interesante discusión acerca de las asimetrías en las relaciones transfronterizas: “...intercambios desiguales de valor económico entre diversos tipos de personas y regiones" (p. 80). El análisis de este fenómeno es vital para entender el funcionamiento de este CUT, debido a que por la manera particular como ambas ciudades se relacionan, en ocasiones se invierte el significado de la relación, y Tacna se muestra como la parte dominante del binomio, cuando en realidad ocurre lo opuesto.

Este artículo se apoya en la investigación interdisciplinaria realizada en el marco del proyecto CONICYT/FONDECYT 1150812 concerniente a la regionalización en el norte de Chile. A partir de una revisión de la bibliografía existente, así como de la recopilación estadística pertinente, se realizó un trabajo de campo que contemplaba observaciones, entrevistas semiestructuradas, talleres y grupos focales. Con el objetivo de viabilizar el proceso investigativo, fueron construidos cuatro ámbitos de relacionamientos -público, transacciones económicas, cotidianeidad y medio ambiente- y cada uno de ellos segmentados en circuitos de relaciones considerados principales en el funcionamiento de la región. Finalmente, en cada circuito fueron identificados actores, colectivos e individuales. Aunque la investigación se realizó primordialmente en Arica, algunos instrumentos fueron aplicados a actores en Tacna, en una suerte de reconstrucción transfronteriza de los procesos. En este ámbito específico las entrevistas se dirigieron a personas relacionadas con los procesos de intercambio y producción: empresarios formales, microempresarios, trabajadores en actividades que articulan los flujos (comerciantes, cargadores, choferes) así como funcionarios relacionados con la gestión de la relación transfronteriza. Todo el material -excepto cuando fue solicitado lo contrario por los sujetosfue grabado y transcripto.

\section{El discreto encanto de la plusvalía absoluta}

Para muchos empresarios chilenos el uso de la fuerza de trabajo barata de Tacna es una tentación irreprimible. Arica sufre vacíos crónicos en su mercado de trabajo debido a que una parte considerable de su fuerza laboral emigra a las regiones mineras más lucrativas de Tarapacá y Antofagasta, donde los ingresos percibidos por ello puede ser hasta de 60\% superior (Collado, 2018). Ello afecta la agricultura, las construcciones y los servicios, y en el caso específico de la primera, la mano de obra peruana resuelve un problema de pérdida de competitividad frente a la emergencia en Tacna de haciendas agrícolas más rentables. Los braceros peruanos llenan un "mercado segmentado" (en el sentido discutido por Piore, 1971) restañando la competitividad de los predios agrícolas circun/ urbanos con sus cuotas de plusvalía absoluta.

Aquí hablamos, ante todo, de los miles de trabajadores peruanos, mayoritariamente hombres jóvenes, que cruzan hacia Arica aprovechando la liberalidad del tránsito de personas en el marco de la Alianza del Pacífico. Pueden hacerlo para seguir camino a otras regiones de Chile (en particular la capital y las regiones mineras del norte) donde permanecen largas jornadas y por lo general devienen migrantes 
indocumentados (Vicuña y Rojas, 2015). O pueden quedarse en Arica, donde trabajan varios días a la semana y regresan periódicamente a sus comunidades en Perú. Ellos son lo que se ha denominado usualmente trabajadores migrantes estacionales o simplemente trabajadores circulares.

Estos flujos de trabajadores, vistos ahora como mercancía/fuerza de trabajo, constituyen un circuito económico complejo. Se inician con la atracción que ejerce Tacna -sea por su dinámica comercial o por su cercanía con Chile- para los sectores campesinos -fundamentalmente aymaras- de la zona de Puno, que se "descuelgan" -para utilizar la locuaz expresión andina- y acuden a la ciudad en busca de oportunidades. De acuerdo con Berganza (2014), esto ha provocado el surgimiento al interior de Tacna de una "frontera cultural" que diferencia a los "tacneños de siempre" de los recién llegados: "...con lo cual se ha transformado la realidad social, económica y política de la ciudad” (p. 174).

Como antes anotaba, cuando estas personas deciden cruzar la frontera para trabajar en Arica, lo hacen respondiendo a la escasez de braceros dispuestos a trabajar por salarios deprimidos en el mercado de trabajo en esta ciudad y sus campos aledaños. Un propietario de un predio agrícola de seis hectáreas en Azapa confesaba serias dificultades para conseguir trabajadores chilenos para su finca:

...iquienes van a hacer las cosechas?, ni un chileno querría trabajar así, a mí mismo me dicen que en Arica no hay trabajo, les digo que si quieren ir a cosechar y se ríen vieran que para otra gente eso es una bendición (hombre chileno, 62 años, propietario agrícola).

La "otra gente" que menciona son los trabajadores peruanos. Desde hace años basa su finca en esa fuerza de trabajo que mediante contratistas que recorren el sur de Perú. "Nunca falta gente" dice. Su opinión acerca de los braceros peruanos vale la pena ser transcripta:

Ahora que hay esfuerzo lo hay, no todos pero algunos vienen con el panorama claro, trabajar de sol a sol, no gastar y luego comprarse algo propio... el peruano es desconfiado y callado con otros peruanos, pero buen trabajador, hace lo que debe hacer, reclama poco, nunca pide permiso, a menos que sea emergencia, puede llegar encañado (ebrio) pero te trabaja igual, entonces no es mi problema, pero pagamos bien, son como 20.000 pesos al día, si hacen más sacos, hay unas monedas extras, es bastante en la semana cuanto y te ahorras la casa, no es malo el trato, que van a hacer, si allá están a penas y acá hay algún futuro.

Los trabajadores peruanos en Arica, aun cuando están en posición relativamente más favorable que otros grupos inmigrantes, sufren como ellos una doble condición de explotación económica y subordinación cultural. Se insertan en la parte inferior de la pirámide social: como trabajadores no calificados, sin estatus legal para trabajar, usualmente desprovistos de contratos y con salarios bajos. La frecuente referencia encontrada en las entrevistas acerca de los trabajadores peruanos como "introvertidos", "nada quejosos" y "dispuestos para lo que haga falta" encierra un drama de una población obligada a hacer lo que los trabajadores chilenos no están dispuestos a hacer. La propia cifra que menciona el empresario -20 mil pesos, al cambio del momento unos 25 dólares- equivale a 3,5 salarios mínimos peruanos. Es decir, sumas relativamente altas, pero que se obtienen trabajando largas jornadas de hasta 12 horas diarias, con alojamientos muy precarios, en las mismas fincas (en ocasiones entre los mismos surcos) o en asentamientos irregulares particularmente deprimidos, desarraigados y expuestos a discriminaciones y abusos. Cargan consigo la doble subordinación remarcada por Fraser (2006) del estatus en el plano cultural y de la clase desde las entrañas de la economía.

Ellos, como ningún otro flujo humano circular Arica-Tacna, ofrecen a la economía capitalista local la ventaja que puntualizó Kearney (2003, p. 52) hace tres lustros: "la separación espacial de los sitios de compra y consumo de la mano de obra desde los sitios de su reproducción, de tal modo que los lugares de producción y reproducción están en dos espacios nacionales diferentes". Y en consecuencia, los primeros se desentienden de los costos de los segundos.

\section{Los itinerarios del comercio hormiga}

Otro circuito principal de la relación transfronteriza es el llamado comercio hormiga, es decir, el trasiego de cantidades significativas de mercancías 
pero transportadas individualmente y en lotes pequeños aceptables para los funcionarios de aduanas. Muestran una suerte de especialización sociológica en dos sentidos. Por un lado, son circuitos copados por mujeres. Por otro lado, son circuitos marcadamente etnizados, en nuestro caso poblados y controlados por personas peruanas y bolivianas, frecuentemente aymaras. Una y otra condición implica efectos positivos en sectores vulnerables socialmente. Por ejemplo, erosiona los aspectos más gravosos de la dominación patriarcal, al contribuir a la independencia económica y a la autoestima de muchas mujeres. También ha resultado un mecanismo importante de incorporación de mujeres migrantes en Arica. Pero no es posible soslayar que por estas mismas razones son actividades relegadas simbólicamente en sociedades patriarcales y nacionalistas, como las que aquí nos ocupan.

La actividad de comercio hormiga más relevante es el tráfico de tejidos usados que corre de sur a norte e involucra a cientos de personas de ambas nacionalidades. Aunque la multiplicidad de personas pobres que se enrolan en esta actividad conduce a la idea de una economía popular, la realidad parece ser la de un flujo husiforme, concentrado en sus extremos (donde se mueven capitalistas medios) y ancho en su centro, donde se genera una capilaridad necesaria para invisibilizar el tráfico. Y es así porque el comercio de tejidos usados en esta frontera no opera, en primera instancia, basado en diferencias de precios sino debido a una situación legal paradójica: el tráfico de ropas usadas está prohibido en Perú, al mismo tiempo que la venta es tolerada en Tacna. De manera que existe un mercado local que tiene que aprovisionarse de manera ilegal, y la mejor manera de hacerlo es aprovechando la permisividad de Arica, cuyo puerto canaliza la mercancía desde las cadenas globales. En consecuencia, los centenares de mujeres peruanas que cruzan los tejidos de manera subrepticia, ponen en contacto y validan dos espacios de acumulación de significación regional -importadores mayoristas y vendedores finales minoristas- $y$ sostienen una forma peculiar de relación con flujos económicos globales.

El comercio de ropas usadas ha sido descripto minuciosamente por Peña (2009) y en su desenvolvimiento ariqueño por Guizardi et al. (2015), lo que me exime de una reseña extendida del asunto. Baste solo decir ahora que desde sus orígenes el flujo de tejidos usados en esta zona se relaciona con el puerto de Arica y con la ZOFRI.
A comienzos del presente siglo, el comercio de ropas estaba controlado por una compañía suministradora ubicada en la extensión de la ZOFRI en Chacalluta, pero cuando se retiró, su espacio fue llenado por varias casas mayoristas importadoras, la mayor parte de ellas ubicadas en el llamado Barrio Industrial. Estas empresas se siguen nutriendo de la ZOFRI y la mayoría de los informantes coinciden en un número cercano a la docena. Sus ofertas van dirigidas principalmente al mercado tacneño pero también al mercado chileno.

Muchas compradoras van directamente a estos galpones a realizar sus compras y reclasificar la ropa adquirida, lo que hacen en las inmediaciones de las instalaciones. Pero la mayor parte de las operaciones tienen lugar en el barrio Juan Noé contiguo a la Terminal de autobuses de donde salen los vehículos hacia Tacna. En este barrio -el lugar por excelencia de concentración de peruanos en Arica- existen almacenes más pequeños donde las mujeres peruanas realizan sus compras que pueden montar directamente en vehículos alquilados o reorganizarlas en paquetes menores en el mismo patio de la terminal de buses. Desde aquí se inicia un itinerario evasivo de los controles fronterizos peruanos hasta la llegada a Tacna, donde la mercancía es reagrupada por sus compradores finales y puesta a la venta en zonas habilitadas de la ciudad.

Una parte de los tejidos de segunda mano que entran a Arica se venden en Chile. Un circuito sigue rumbo al sur, hasta Santiago, mientras el otro se queda en Arica donde existe un floreciente mercado en las zonas aledañas al terminal agropecuario (ASOCAPEC) y en varias ferias en distintos puntos de la ciudad. Más de la mitad de las vendedoras de la ASOCAPEC -calculadas por un dirigente de la asociación en trescientas- son mujeres peruanas y bolivianas residentes en la ciudad. Su presencia mayoritaria en esta actividad tenía que ver con sus reconocidas habilidades comerciales (arraigadas en la cultura aymara), pero también con la ventaja que significaba el proceso de etnización del circuito, el hecho de que el comercio ha estado controlado por personas peruanas que prefieren tratar con sus connacionales, entre otras razones porque compran más regularmente y pagan en dólares.

Curiosamente, algunas mujeres chilenas compraban ropas usadas en Tacna, para luego revenderlas en Arica, en la consideración del buen trato que recibían en Tacna y de que la mercancía, ya pasado el tamiz de la selección, era de calidad superior. 
Se trataba principalmente de vendedoras de pocas cantidades, precios mayores y clientes selectos. Para ello realizaban viajes personales o usaban a terceras personas, regularmente mujeres peruanas. Una comerciante que se enorgullece de tener entre sus clientes a muchos profesionales - “...y hasta regatean los precios..."- que ya no consideran lesivo a sus estatus vestir con prendas de segunda mano-, describía así su "plan de negocios":

...También he comprado ropa de marca en Tacna. Primero que todo, yo iba a Tacna, iba y compraba por dos, tres prendas, cuatro prendas y con el tiempo me di cuenta que había gente de Tacna que pasa cosas y se les paga a ellos una cantidad de dinero, por prenda generalmente, las poleras de marca, las casacas de marca [...] El método de ellas es que uno le pasa la cantidad, por ejemplo 10 prendas. Le puede pagar la mitad o se les paga acá en Arica, cuando llegan. Estas pasantes trabajan todo el día, pero solo después de las 8 de la noche llegan a pasar las cosas. Ellas juntan de muchas gentes y las marcan, les ponen el nombre de uno... y después cuando ellas llegan acá en el terminal internacional le entregan las prendas y uno termina de pagarle lo que le piden.. (mujer chilena de 34 años, comerciante).

En resumen, la ropa usada entra por el puerto de Arica y es transportada por mujeres peruanas hacia Tacna, donde mujeres chilenas la encargan para ser devuelta y vendida en Arica, posiblemente transportada por las mismas mujeres que las llevaron en dirección opuesta.

El movimiento circular de mujeres peruanas y chilenas conlleva otra modalidad de comercio hormiga, pero en otra dirección: hacia Arica. Se trata de personas que transportan bienes no duraderos peruanos por encargo de terceros o para aprovisionar negocios propios. En muchos casos son las mismas mujeres "cachineras" peruanas que en sentido opuesto trafican la ropa usada, pero también hay un sector más especializado que solamente se dedica a este rubro. Son denominadas comisionistas.

Es el caso, por ejemplo, de una mujer joven tacneña que se estrenaba en sus 40 , y había dejado su empleo en su ciudad como técnica en contabilidad, para radicarse en Arica como pequeña negociante. Cambió varias cosas, afirmó, como su profesión por más ingresos y su identidad aymara que en Perú le era reconocida, pero "....acá solo soy extranjera". Tiene un pequeño negocio en Arica que solo funciona unos días a la semana. Por ello, su actividad más lucrativa reside en comprar en Tacna encargos de comerciantes chilenos, lo que realiza "impecable" debido a su condición privilegiada en relación con los circuitos peruanos. "Sé a dónde ir y a quién preguntar" fue su respuesta a la pregunta acerca de la causa de la rentabilidad de su actividad: "Pero esos movimientos cansan, y nada ahí es seguro".

Peña (2009) -desde el periodismo de investigación- nos ofrece una descripción del movimiento en la terminal de buses de Tacna, un lugar donde se aglomeran bultos, comerciantes, cambistas y todos quienes tienen que ver con estos tráficos que nunca terminan:

Es mediodía y el terminal terrestre internacional está copado de comisionistas que van y vienen intercambiando productos... Los comisionistas, que en su enorme mayoría son mujeres, se pasan el día haciendo trueque. Cinco películas por dos polos (buzos). Dos polos por un par de zapatillas. Un par de zapatillas por dos camisetas deportivas. Dos camisetas deportivas por un par de jeans. Un par de jeans por cinco películas, y así. La idea es que al final del día, antes de embarcarse rumbo a Arica, hayan logrado hacer cuadrar la cuota máxima de productos que permite ingresar la aduana chilena sin pagar impuestos. Técnicamente no es contrabando. No al menos mientras se cruza la frontera. Pero una vez en Chile esos productos dispersos volverán a reunirse para que su verdadero propietario lo distribuya en el comercio (Peña, 2009).

Más allá de estos casos de dedicación profesional al tráfico hormiga, la realidad de esta frontera es una circulación incesante de bienes cuya ubicación en lo lícito o lo ilícito se hace indistinguible. Y es usual que una misma persona viaje a Tacna para cumplir fines distintos -consumos lúdicos o de servicios personales, comerciales, familiares-, pero que en la práctica se mezclan.

Una mujer chilena cercana a los 60 es dueña de una pequeña tienda cuyas ventas implican dos productos claves del tráfico hormiga hacia Arica: licores 
y cigarrillos. Ella organiza semanalmente un viaje a Tacna con un grupo de amigas. Van a restaurantes y pasean por la ciudad. El grupo compra productos para fines diversos y organizan sus paquetes para no sobrepasar las cantidades permitidas. Finalmente ella recoge la mayor parte de esa mercancía y la revende en su negocio, a precios menores que los chilenos y casi siempre a clientes fijos. Para cubrir cualquier inspección fiscal, compra algo de la misma marca en el mercado chileno y guarda las boletas.

Por último, vale la pena anotar que aunque este tipo de comercio hormiga hacia Arica lo practican personas de ambas nacionalidades, no lo hacen con igual suerte. Aquí la frontera desempeña su rol clasificador, "...como filtros selectivos que permiten pasar ciertas cosas y no otras" (Kearney, 2008: 97). Una comerciante chilena lo dijo casi en susurro, pues "suena feo",

"pero en el control de Chile, cuando te ven cara de chilena no te paran, tú puedes pasar, yo una vez pasé 5 botellas sola y me dejaron pasar. Y atrás mío venía una paisanita que venía con 7 poleras y la hicieron parar y le quitaron las poleras.

Me acuerdo una vez que vi a una señora que pasó una bolsa matutera llena de estas cosas como quinua, y sí, le hicieron caleta de drama pero igual es como bien discriminatoria la weá porque ella tenía pinta de chola... Pero nosotros igual hemos pasado bolsas matuteras y nada" (mujer chilena, comerciante, 52 años).

\section{Hospitales, mercados y prostíbulos: el consumo chileno en Tacna}

Si el flujo predominante de peruanos que cruzan a Arica son vendedores de fuerza de trabajo, los chilenos que cruzan en sentido inverso son consumidores de mercancías. En cierta medida dimos cuenta de este fenómeno al analizar el comercio hormiga, pero esta modalidad es un componente menor y eventual. La función principal de Tacna es la provisión de servicios y bienes a los ariqueños a precios menores o en mejores condiciones de provisión que los que pueden encontrar en su lugar de residencia. De manera que si en referencia a los trabajadores circulares tacneños el capitalismo chileno se beneficia con la separación de los lugares de producción y de reproducción familiar; el consumo chileno en Tacna produce otro tipo de separación entre el lugar de la venta de la fuerza de trabajo y el lugar del consumo para la reposición de esa fuerza.

Según los datos obtenidos de la Dirección General de Migración y Naturalización en Tacna, en 2015 cruzaron a esta ciudad por Chacalluta/ Santa Rosa 1.684.421 personas extranjeras, casi todas chilenas, el doble de las que lo hicieron en 2009. Aunque el $11 \%$ eran propiamente turistas que pernoctaban en la ciudad, el resto solo pasaba un día. Los primeros gastaban 64 dólares diarios, y los segundos 56. En total dejaban a la ciudad unos 100 millones de dólares anuales.

Según una encuesta realizada por ZOFRATACNA (2016) a 407 chilenos visitantes, el 35\% de ellos tenían como finalidad principal la recreación, básicamente gastronómica; el 34\% los cuidados de salud y el 22\% hacer compras. Finalmente, el 79\% de los encuestados compraban algo: ropas (67\%), bebidas alcohólicas y cigarrillos (19\%) y zapatos (11\%). La encuesta mostraba un uso diferenciado de Tacna según los recursos económicos: las familias más pobres la usaban por sus precios convenientes, mientras que los grupos con más ingresos enfatizaban el lado lúdico y la variedad de ofertas. El 74\% eran ariqueños, el $12 \%$ santiaguinos y $9 \%$ iquiqueños.

Varias personas entrevistadas eran consumidoras usuales en Tacna. Una mujer en sus 40, de un estrato de ingresos bajos, señala que solo hace compras relacionadas con artículos de higiene (como papel sanitario y detergente), alimentos envasados y cigarrillos, todo ello lo adquiere en el Mercado Central. Viaja 6 o 7 veces al año, aunque también se auxilia de sus padres que viajan mensualmente. En la entrevista mostró un conocimiento exacto de los precios en Tacna y los ahorros que implicaban, lo que se aproximaba, afirmaba, al 50\% del gasto que hubiera hecho en Chile.

Según las entrevistadas se aproximaban a un estatus de clase media, variaba el tipo de producto que adquirían y perdían el control contable de la operación. Es el caso de otra mujer, profesional con 34 años, que fijaba su atención en consumos selectivos como café, condimentos, cigarrillos y licores. Viaja a Tacna cada dos meses con su pareja, con propósitos múltiples:

Lo primero siempre es la recreación y salir y comer y tomar, despejarse y estar desconectado de los celulares... Entonces son como uno o dos días donde uno puede 
relajarse y aprovecha de comprar, porque es como idiota ir a Tacna y no comprar.

La joven profesional toma a Tacna por su lado glamoroso: su conversión en una suerte de playa de ocio para los chilenos. La ciudad ha logrado dotarse de una red de restaurantes económicos y de alta calidad, hoteles de varias gradaciones y casinos que fascinan a los visitantes ariqueños. "En los casinos, comentaba un ariqueño joven que visita Tacna casi todos los fines de semana, te dan el trago gratis mientras juegas, pero en Chile hay que pagarlo" (hombre chileno, chofer de camiones de carga, 33 años). Estos establecimientos se ubican generalmente en un circuito de tránsito de los chilenos (Avenidas Bolognesi, San Martín y Coronel Mendoza), alejándose del centro según se incrementa el tono pecaminoso del consumo. En las afueras, en la zona de Alto Chorrillo, funcionan los burdeles especializados para los chilenos (Las Cucardas, El Venus, Las Pasiones), donde los precios por una tanda de sexo son $25 \%$ del servicio en un prostíbulo ariqueño.

Otra razón de visita asidua de los chilenos es el consumo de servicios médicos. Según Liberona, Tapia y Contreras (2017), el 40\% de los cruces de chilenos respondía a esta razón, en su inmensa mayoría cruces de un solo día, lo que permite afirmar que "...la movilidad por salud es una alternativa para los y las ariqueñas(os), y chilenos del Norte de Chile, especialmente por la dificultad para acceder a la atención de especialistas en Arica e Iquique, en contraste con la facilidad para acceder a la atención de especialistas en Tacna" (p. 269).

Este consumo se realiza principalmente en dos áreas.

La primera es el Hospital de la Solidaridad de Tacna, un componente de la red del Sistema Metropolitano de Salud (SISOL) que recibió -según las estadísticas de la entidad- la visita en 2016 de 59.766 personas chilenas, el $71 \%$ de Arica, lo que significaba el $45 \%$ de la totalidad de las consultas del hospital. Los chilenos frecuentaron las 33 especialidades que se ofrecían.

La segunda es la red de farmacias, ópticas, gabinetes odontológicos, y otros establecimientos accesorios a todo lo largo de aquellos lugares por donde se mueven los visitantes chilenos, en particular en la emblemática avenida Bolognesi. Son establecimientos pequeños, que están adaptados para un servicio rápido de precios muy moderados para los ingresos chilenos. Unos lentes bifocales, por ejemplo, se pueden adquirir en tres horas y a un tercio del precio en Arica, donde demoran 15 días.

Todos las personas entrevistadas (seis) coincidieron en que el consumo en Tacna representaba ahorros significativos para sus economías familiares. Un sondeo realizado a partir de los productos que declaraban comprar, las cantidades y los precios comparados del Mercado Central de Tacna y del ASOCAPEC de Arica, arrojó ahorros mensuales de entre 43 mil y 59 mil pesos por familia. Pero en dos casos en que las personas también requerían tratamientos médicos y compras de medicinas, los ahorros ascendieron a 143 mil y 223 mil pesos mensuales. Datos muy relevantes para una región como Arica, donde el ingreso medio en 2017 era de 413 mil pesos (Collado, 2018).

\section{La acumulación y las lentejuelas}

Obviamente, ambas ciudades se benefician sustancialmente del funcionamiento del complejo urbano transfronterizo. Pero, como advertíamos antes, se trata de una relación compleja en que, al decir de un anciano ariqueño que afirma "haberlo visto todo", "todo vuelve", y las apariencias se superponen a la realidad. Tacna aparece entonces como la ciudad que prospera respecto del estancamiento de Arica -en esto coinciden todos, chilenos y peruanos-, lo que es solo parcialmente cierto. Y lo que resulta aún más importante, no es cierto en lo fundamental. Creerlo es confundir lentejuelas con acumulación.

La dinámica de Tacna es impresionante. Desde 1940, en que era un poblado de 11 mil habitantes, su población ha crecido hasta convertirse en una urbe regional de más de 300 mil habitantes, superior en más de un tercio de la población de Arica. Sus indicadores económicos y de bienestar social también han mejorado y hoy se ubica como una de las ciudades menos pobres del Perú.

En buena medida este resultado ha estado ligado a políticas nacionales, incluyendo a las que han tratado de dar una acogida calurosa a la ciudad retornada tras décadas de secuestro chileno. Pero no siempre ha sido así, y de cualquier manera si estas políticas nacionales han sido tan exitosas se debe a la existencia de un entramado empresarial y político regional capaz de aprovechar las oportunidades de la frontera. 
El punto neurálgico de esta dinámica ha sido la Zona Franca de Tacna (ZOFRATACNA). Paulatinamente moldeada desde 1989 y finalmente decretada en 2002, la ZOFRATACNA ha sido particularmente exitosa en el copamiento del comercio regional - para lo que tuvo que horadar la hegemonía de la ZOFRI- y su organización desde una perspectiva transfronteriza. Un alto directivo de la organización fue explícito en su visión de la relación con Arica: "El chileno mueve a Tacna... la única manera de vender Tacna para los peruanos es venderla con Arica... si Arica crece es más fácil ofertar a Tacna" (hombre peruano, 56 años, empresario).

Debido a su relevancia económica, este complejo económico ha sido un partícipe directo de varios organismos colegiados y en la formulación de políticas públicas locales. Lo que ha creado en Tacna un sector empresarial con un discurso y una visión de futuro más sofisticados que sus homólogos ariqueños, cuyos puntos de vista -salvo excepciones- no rebasan los resentimientos de un sujeto desfavorecido por la vida.

Por otro lado, la dinámica mencionada ha dotado a la ciudad de una infraestructura de servicios envidiable, tanto por su infraestructura como por su capacidad de respuesta ante una demanda variada y puntual. De acuerdo con la información oficial suministrada por la Dirección Regional de Comercio Exterior y Turismo de Tacna y por el Servicio Nacional de Turismo de Arica, la infraestructura de servicios era muy desbalanceada. Tacna, por ejemplo, posee 369 hoteles, 89 de ellos categorizados, así como 332 restaurantes, diez de ellos con categorías superiores. Arica, que tiene atractivos geográficos, históricos y culturales envidiables, solo posee 117 instalaciones hoteleras, la abrumadora mayoría pequeñas unidades con menos de 20 habitaciones y unos 160 restaurantes, ninguno con un pedigrí reconocido. Se trata de una situación desbalanceada en la que también ha incidido la incapacidad de la clase empresarial local para una gestión más efectiva, que le permita aprovechar la concurrencia turística en la ciudad vecina -miles de chilenos que cruzan a Perú desde Arica o de peruanos que visitan Tacna- o su posesión de un puerto que recibe eventualmente cruceros turísticos.

No se puede negar el impacto positivo que esto tiene en la ciudad de Tacna. Pero cualquier acercamiento racional a esta relación sugiere de inmediato un callejón sin salida: el atractivo definitivo que tiene Tacna sobre Arica no es, en lo fundamental, la calidad de sus servicios, sino sus precios. Estos precios pueden conseguirse por diferentes estrategias comerciales -por ejemplo mediante la economía de escala- que los empresarios de ZOFRATACNA conocen y saben usar. Pero el factor decisivo es indudablemente el desarrollo desigual. En consecuencia, en el marco de una relación sistémica muy contradictoria, la ciudad tiene a su pobreza relativa como su carta principal. Y Arica, aun cuando efectivamente desaprovecha oportunidades debido a la incapacidad de empresarios y políticos, saca las mejores partidas de esa pobreza. Miles de braceros hacen producir en condiciones de alta rentabilidad las franjas agrícolas de Azapa y Lluta, llenando el vacío que dejan miles de braceros ariqueños que se emplean en las zonas mineras mejor pagadas de Tarapacá, Antofagasta y Copiapó. Sus economías familiares se benefician de los bajos precios de los servicios y los bienes en Tacna, sea buscando salud, divirtiéndose o llenando los anaqueles de las despensas. El uso del puerto por las empresas tacneñas no solo contribuye a su funcionamiento, sino que también genera actividades de transporte y acarreo que es realizado por compañías chilenas. El conflicto -expreso o subyacente- es la cualidad relacional que da vida a este intenso complejo urbano transfronterizo.

Tacna debe asumir ciertos costos invisibles derivados de su relación con Arica. En otras partes de este artículo hemos comentado algunos, como la recepción de flujos de personas pobres -peruanos y sudamericanos- atraídos por las oportunidades, siempre insuficientes, de la ciudad. Tacna deviene una ciudad de territoriantes, "habitantes a tiempo parcial" (Muñoz, 2008, p. 27) que solo consumen fragmentos de ciudad. Sus zonas centrales no se definen por la fijación, sino por el movimiento. $\mathrm{Y}$ aun cuando constituyen lugares intensos de la reproducción material de la ciudad -y por consiguiente, lugares efectivos de trabajo para miles de peruanos- se erigen como clásicos "no lugares" para los cientos de miles de visitantes-compradores. Citando a Augé (2000), como “...palimpsestos donde se reinscribe sin cesar el juego intrincado de la identidad y de la relación" (P. 45). La ciudad, por consiguiente, está obligada a dirigir una buena parte de su inversión pública hacia estos fragmentos urbanos que deben garantizar seguridad, higiene y diversión a los visitantes y turistas. 
Hipotéticamente se pudiera argumentar que estas condiciones pudieran cambiar si esta región se ubicara en una posición estratégica en relación con los procesos de reterritorialización que ocurren en las riberas del Océano Pacífico, y en particular al calor de los Corredores Bioceánicos (CB) que patrocinan los proyectos integracionistas regionales. Estos CB constituyen procesos de colonización y acumulación por desposesión (Harvey, 2003) en función del capital global y en particular de sus núcleos asentados en la zona de São Paulo. Sus desarrollos supondrían grandes procesos de reestructuración territorial en la zona, que dejaría de ser esa territorialidad cautiva que discutíamos para devenir eslabones de cadenas de valores transnacionales.

\section{Agradecimientos}

Este artículo es parte del proyecto FONDECYT 1150812, La regionalización transfronteriza en el norte de Chile. Han contribuido a él en diferentes momentos de la investigación, Camila Álvarez, Nicolás González, Damarys Vilca, Camila Contreras y Felipe Valdebenito. No menos significativo es el aporte de los evaluadores cuyos comentarios críticos han sido de gran valor para un mejoramiento teórico de la versión final.

\section{Referencias Citadas}

Aduana de Chile

2016 Anuario Estadístico. Santiago de Chile

Augé, Marc

2000 Los "No Lugares" Espacios del Anonimato, Gedisa Editorial, Barcelona.

Benedetti, Alejandro

2014 "Espacios Fronterizos del Sur Sudamericano". Estudios Fronterizos, nueva época, vol. 15, núm. 29, enero-junio de 2014, pp. 11-47.

Berganza, Isabel

2015 "La Migración Peruana en Zonas Fronterizas", en Regiones Fronterizas: Migración y los Desafíos Para los Estados Nacionales Latinoamericanos (Edit. por M. Tapia y A. González), Ril Editores, Santiago, pp. 153-176.

Collado, María J.

2018 "Arica es la región con ingresos más bajos en el Norte y la segunda a nivel del país", Estrella de Arica, 19 de junio. Contreras, Yasna, M. Tapia y N. Liberona

2017 "Movilidades y prácticas socioespaciales fronterizas entre Arica y Tacna. Del sentido de frontera a la transfrontericidad DEM entre ciudades", Diálogo Andino No 54, pp. 127-141.

2016 Migración en Chile 2005-2014. Departamento de Extranjería y Migración del Ministerio del Interior y Seguridad Pública. http://www.extranjeria.gob.cl/media/2016/02/ Anuario-Estad\%C3\%ADstico-Nacional-Migraci\%C3\%B3nen-Chile-2005-2014.pdf

Díaz-Araya, Alberto y E. Sánchez

2016 "Migración, fronteras, asentamientos e indígenas", Diálogo Andino $\mathrm{N}^{\circ} 51$.

Dilla, Haroldo

2015 "Los Complejos Urbanos Transfronterizos en América Latina". Revista de Estudios Fronterizos, Nueva Época, Vol. 16, No 31: 15-38.

Dilla, Haroldo

2016 "La Regionalización Precaria en la Frontera Haitiano/ Dominicana", en Si Somos Americanos, Vol. XVI, N.1, enero-junio, pp. 7-22.

Domínguez, Ana Rosa

2010 "La Organización Social de las Fronteras: Etnografía de la Cotidianeidad Fronteriza Chuí/Chuy", en Miradas
Comparativas Sobre las Fronteras en América Latina (Edit. por Carlos A. Casas y M. Ortolan), Miguel Ángel Porrúa, México DF, pp. 123-142.

Emmanuel, Arghiri

1972 El Intercambio Desigual, Siglo XXI Editores, México.

Foucault, Michel

2003 Vigilar y castigar, Siglo XXI Editores, México.

Fraser, Nancy

2006 "La Justicia Social en la Era de la Política de la Identidad”, en (N. Fraser y A. Honneth), ¿Redistribución O Reconocimiento?, Morata, Madrid.

González, Sergio

2008 La Llave y el Candado, LOM Ediciones, Santiago de Chile.

Guizardi, Menara, et al.

2015 "Condensaciones en el Espacio Hiperfronterizo: Apropiaciones Migrantes en la Frontera Norte de Chile", en Las fronteras del Transnacionalismo (Edit. por M. Lube y A. Grinsom), Ocho Libros, Santiago, pp. 224-256.

Harvey, David

2003 El nuevo imperialismo, Akal, Madrid.

Harvey, David

2007 Espacios del capital, Akal, Madrid.

Kearney, Michael

2003 "Fronteras y límites del Estado y el Yo al final del imperio". Alteridades $\mathrm{N}^{\circ} 13$ (enero-junio). www.redalyc. org/articulo.oa?id=74702506>

Kearney, Michael

2008 "La Doble Misión de las Fronteras como Clasificadoras y Como Filtros de Valor", en Migración, Fronteras e Identidades Étnicas Transnacionales (edit. por Laura Velasco), Miguel Ángel Porrúa, México, pp. 79-116.

Mezzadra, S. y B. Neilson

2013 Border as a Method or the Multiplication of Labor, Duke University Press, Durham.

Jessop, Bob

2001 "The Political Economy of Scale", In Globalization, Regionalization and Cross Border Regions (Edit. By M. Perkmann and N. Lin Sum), Palgrave, London, pp. 25-46. 
Liberona, Nanette, M. Tapia y Y. Contreras

2017 "Movilidad por salud entre Arica y Tacna: análisis de una demanda no satisfecha y de una oferta atractiva del otro lado de la frontera", en Geopolítica, 8(2) 2017, pp. 253-278.

Montenegro, Silvia y V. Giménez

2006 La triple frontera: globalización y construcción social del espacio, Miño y Dávila Editores, Buenos Aires.

Muñoz, Francesc

2008 Urbanalización, Editorial Gustavo Gili, Barcelona.

Nogueira, Ricardo

2008 "Tabatinga: una Ciudad en la Frontera de la Amazonia", en Ciudades en la Frontera (Edit. Por H. Dilla), Editora Manatí, Santo Domingo, pp. 97-125.

Oddone, Nahuel y Eduardo Galantini

2015 "Por la Triple Frontera más Austral de América: un Recorrido por Monte Caseros, Bella Unión y Barra do Quaraî", en Fronteras y Procesos de Integración Regional, (Edit. Por María Barajas, P. Wong y N. Oddone), Juan Pablos Editor, México, pp. 333-355.

Peña, Cristóbal

2009 "Vida al Límite en la Frontera con Perú (I): El Incontenible Flujo del Contrabando Hormiga", Obtenido de http://ciperchile.cl/2009/08/27/vida-al-limite-en-la-fronteracon-peru-i-el-incontenible-flujo-del-contrabando-hormiga/

Piore, Michael

1971 "The Dual Labor Market: Theory and Implications", in Problems in Political Economy: An Urban Perspective. (Edit. by M. Gordon), Heath, Lexington.
Ruiz, Carlos E. y G. Martínez

2015 "Comercio Informal Transfronterizo México-Guatemala

Desde una Perspectiva de Frontera Permisiva”, en Estudios

Fronterizos, nueva época, vol. 16, núm. 31, enero-junio de 2015, pp. 149-174.

Sassen, Saskia

2010 Territorio, Autoridad y Derechos, Katz Editores, Madrid.

Sohn, Christophe

2014 "Modelling Cross-Border Integration: The Role of Borders as a Resource", Geopolitics, 19:3, 587-608, DOI: 10.1080/14650045.2014.913029.

Tapia, Marcela, N. Liberona y Y. Contreras

2017 "El Surgimiento de un Territorio Circulatorio en la Frontera Chileno-Peruana: Estudio de las Prácticas Sociospacial Fronterizas" Revista de Geografía Norte Grande, 66: 117-141.

Tarrius, Alain

2000 "Las Circulaciones Migratorias: Conveniencia de la Noción de Territorio Circulatorio", en Relaciones, Vol. XXI, \# 83, pp. 39-66.

Valero, Mario

2002 Las Fronteras como Espacios de Integración, Caracas, Fondo Editorial Tropykos.

Vicuña, J. y Rojas, T.

2015 Migración en Arica y Parinacota. Panoramas y tendencias de una región Fronteriza. Santiago, Servicio Jesuita a Migrantes.

Zofratacna

2016 "Perfil del Visitante del Día Chileno que Arriba a Tacna", Informe de investigación, Agosto, Tacna.

\section{Notas}

1 Por ejemplo, la incidencia de este asunto en la manera cómo los habitantes de la región perciben las escalas políticas. Contreras, Tapia y Liberona (2017) lo anotaron dejando abierto un camino para investigaciones futuras: "Gran parte de los entrevistados manifiestan que los litigios fronterizos, desde una óptica nacional, no afectan el sentido, la temporalidad ni la recursividad de los movimientos entre territorios. Las fronteras se desdibujan a partir de la cotidianeidad y complementariedad en las prácticas productivas y reproductivas" (p. 138). No menos relevante es la incidencia en este proceso de las identidades ancestrales, reprimidas por las definiciones westfalianas, un repaso a ello puede hallarse en el número 51 de Diálogo Andino (Díaz-Araya y Sánchez, 2016).

2 Tapia, Liberona y Contreras (2017) aplicaron una encuesta aleatoria no probabilística respecto de 240 viajeros en Chacalluta. La persona peruana más usual era un hombre joven que viajaba solo. El 36\% declaraba viajar para trabajar, $29 \%$ por comercio y $20 \%$ por un dudoso "motivos personales". La persona chilena era con mayor frecuencia una mujer de mediana edad que viajaba acompañada. El $40 \%$ buscaba servicios de salud, el $33 \%$ consumos lúdicos, el $10 \%$ compras y el $11 \%$ motivos personales. 
